\title{
Electrophysiological features of Guillain-Barré syndrome in Mongolian adult patients
}

\author{
Gantuya Gantumur ${ }^{1}$, Munkhbayar Rentsenbat ${ }^{2}$, Sarangerel Jambal ${ }^{2}$ and Byambasuren Dagvajantsan ${ }^{1, *}$ \\ ${ }^{1}$ Department of Neurology, School of Medicine, Mongolian National University of Medical Sciences, \\ Ulaanbaatar, Mongolia. \\ ${ }^{2}$ Reflex Neurological Clinic, Ulaanbaatar, Mongolia. \\ *Correspondence: byambasuren@mnums.edu.mn; Tel.: +976-9901-1455
}

Received: 4 July 2021; Accepted: 1 August 2021; Published: 26 August 2021

Edited by: Battuvshin Lkhagvasuren (Mongolian National University of Medical Sciences, Mongolia) Reviewed by: Gantsetseg Tumur-Ochir (Mongolian National University of Medical Sciences, Mongolia); Hui Jan Tan (Universiti Kebangsaan Malaysia, Malaysia) https://doi.org/10.31117/neuroscirn.v4i3Suppl.98

\begin{abstract}
The Guillain-Barré syndrome (GBS) is a rare but severe disorder that affects peripheral nerves and is classified into several subtypes based on clinical presentation and electrophysiological abnormalities. Incidence and predominant subtypes of GBS differ geographically. The diagnosis is made upon clinical features and confirmed by nerve conduction studies (NCSs) which can differentiate subtypes such as demyelinated and axonal. Demyelinating subtypes in Europe and North America and axonal subtypes in Asia are predominant. Electrophysiological subtypes have not been determined in Mongolia. Therefore, we aimed to determine common electrophysiological subtypes of Guillain-Barré syndrome in Mongolia. In our study, 75 patients referred to Reflex Neurological Clinic between 2016 and 2019 were retrospectively reviewed. After excluding the cases by the criteria, patients were classified as demyelinating, axonal, normal and equivocal subtypes based on Hadden criteria. We compared the electrophysiological features of axonal and demyelinating subtypes. SPSS-23 was used for statistical analysis. The results are expressed in averages (standard deviations) and percentages (numbers). The difference between the mean and the group of variables was calculated using the T-test and the Chi-square test. Patients were $44 \%$ male (33), and the mean age was $46.4 \pm 15.1$. There was no significant association between seasonal factors and electrophysiological subtypes. Among 75 patients with Guillain-Barré syndrome, a nerve conduction study was performed in the first week on $36 \%$ of patients, $33.3 \%$ in the $2^{\text {nd }}$ week, and others in the $3^{\text {rd }}-4^{\text {th }}$ week after symptom onset. Electrophysiology subtypes were classified as demyelinating (65.3\%), axonal (20\%), within the normal range (5.4\%) and equivocal (9.3\%) based on Hadden criteria. The absence of F-waves on electrophysiological examination was higher in patients within 14 days of the disease onset, whereas non-sensory changes were higher in patients after 14 days. We conclude that acute inflammatory demyelinating neuropathy (AIDP) was the most frequent subtype of GBS in Mongolia.
\end{abstract}

Keywords: Guillain-Barré syndrome; nerve conduction study; electrodiagnostic criteria; electrophysiological subtypes;

(C2021 by Gantumur et al. for use and distribution according to the Creative Commons Attribution (CC BY-NC 4.0) license (https://creativecommons.org/licenses/by-nc/4.0/), which permits unrestricted non-commercial use, distribution, and reproduction in any medium, provided the original author and source are credited.

\subsection{INTRODUCTION}

The Guillain-Barré syndrome (GBS) is a rare but severe disorder that affects peripheral nerves and spinal roots, classified into several subtypes related to clinical presentation and electrophysiological abnormalities (Doorn, 2020; Willison et al., 2016). The diagnosis is 
made based upon clinical features and confirmed by nerve conduction studies (NCSs) which can differentiate subtypes such as demyelinating and axonal (Papri et al., 2021; Willison et al., 2016). NCSs are the most informative test to confirm the diagnosis and detect abnormalities in an early stage of the disease within two weeks (Burns, 2008; Hadden et al., 1998). Up to the 1980s, GBS was considered a single disease entity with an immune-mediated attack on myelin components, resulting in demyelination and secondary axonal damage (Shahrizaila et al., 2021). Axonal form of GBS was first termed by Feasby and colleagues (1986), and acute motor axonal neuropathy (AMAN) was defined subsequently in the 1990s. These two terminologies have contributed to change the general understanding of the disease. The two most predominant subtypes are identified as acute inflammatory demyelinating polyneuropathy (AIDP) in Europe and the USA and acute motor axonal neuropathy (AMAN) for Northern China and Japan (Doets et al., 2018). Since the disease subtypes affect the clinical presentation, recovery, and prognosis, it is essential to study the most common electrophysiological subtypes in their countries.

In Europe and Northern America, the demyelinating subtype is predominantly $69-90 \%$ of the cases, and the axonal subtype occurred $3-17 \%$ among the cases (Kuwabara \& Yuki, 2013). The prevalence of axonal subtype is higher in Asia; for instance, it was $65 \%$ in China, and $56 \%$ in Bangladesh after diarrhoea caused by Campylobactery jejuni. Campylobactery jejuni infection spreads more in summer and autumn and is associated with a poor hygienic infrastructure (Bae et al., 2014). Mongolia is an Asian country with underdeveloped systems for fresh and savage water (Asian Development Bank, 2020). Therefore, the axonal subtype after diarrhoea could be higher in Mongolia. The study aims to determine the common subtype of GBS in Mongolia and hypothesized that the prevalence of axonal subtypes could be relatively high.

\subsection{MATERIALS AND METHODS}

According to the following criteria, a total of 104 patients suspected of GBS were referred to Reflex neurological clinic between 2016 and 2019, 75 patients included in this retrospective study: 1 . Fulfilled the National Institute of Neurological Disorders and Stroke diagnostic criteria for the GBS; 2 . Above 18 years of age; 3. NCSs were performed within 28 days after the onset of symptoms. The exclusion criteria are shown in Figure 1. SPSS-23 was used for statistical analysis. The average analysis was performed because the data distribution was normal. The results are expressed in averages (standard deviations) and percentages (numbers). The difference between the mean and the group of variables was calculated using the T-test and the Chi-square test.

The patients were diagnosed based on clinical features and electrophysiological findings. All patients underwent standardized electrophysiological examinations following the methods for precautions of safety, measurements and electrode placement (Kimura, 2013). NCSs were performed for all patients with Nihon Kohden Neuropack S1, four-channel machine using surface electrodes and a stimulator. Standard motor and antidromic sensory NCSs were performed in at least four motor nerves (median, ulnar, peroneal and tibial) and four sensory nerves (median, ulnar, superficial peroneal and sural). Electrophysiologic data involving motor nerves, compound muscle action potential (CMAP), conduction velocity (CV) and distal latency (DL) was evaluated. F wave minimal latency was measured after supramaximal 10 F-waves. The amplitude of sensory nerve action potential (SNAP) and sensory CV was measured in all sensory nerves. Abnormal nerve conduction study measures were defined as those with amplitude lower than and slowed nerve conduction velocity relative to the standard values of electrodiagnosis in diseases of nerve and muscle (Kimura, 2013). Electrophysiological studies were evaluated following the criteria of Hadden. The study was approved by the Research Ethics Committee of Mongolian National University of Medical Sciences under the number of 2019/3-13.

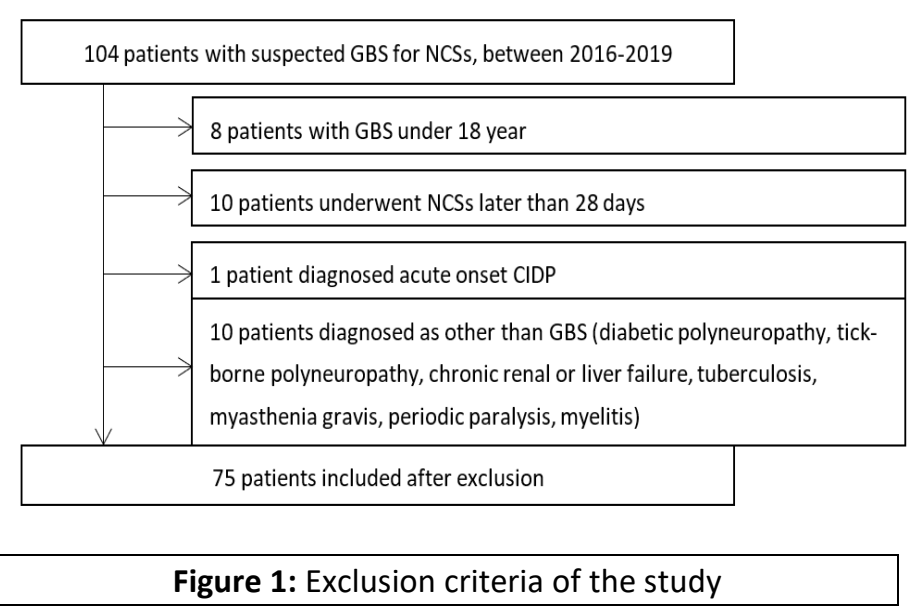

\subsection{RESULTS}

Seventy-five patients were included in the final analysis after exclusion. Patients were $44 \%$ male (33), and the mean age was $46.4 \pm 15.1$. $30 \%$ of patients had a preceding infection before the onset of the GBS. The 
incidence of GBS was highest in the autumn (32\%) and lowest in winter (16\%). However, there was no association between electrophysiological subtypes of GBS and seasonal factors ( $p=0.908)$. Among 75 GBS patients, NCSs was performed $36 \%$ in the first week, $33.3 \%$ in the $2^{\text {nd }}$ week and others in the $3^{\text {rd }}-4^{\text {th }}$ week of symptom onset (Table 1 ).

Electrophysiology subtypes were classified as demyelinating (65.3\%), axonal (20\%), within the normal range (5.4\%) and equivocal (9.3\%) with Hadden criteria (Figure 2). Peripheral motor neuron, sensory neuron and $F$ waves were compared between axonal and demyelinating subtypes. In motor NCSs, there was a significant difference in DL of peripheral nerves, except for n.tibialis, in demyelinating and axonal subtypes. CMAP was significantly different only in n.peronalis (Table 2). Considering the difference of sensory nerves in axonal and demyelinating subtypes, it more dominantly decreased in amplitude changes on the upper limb and no sensory response on the lower limb (Figure 3). As the F-wave response, the absence of $F$ wave response was more than $50 \%$, and the prolonged response was observed in the demyelinating subtype, whereas the $F$ wave was not recorded in the axonal subtype (Figure 4).

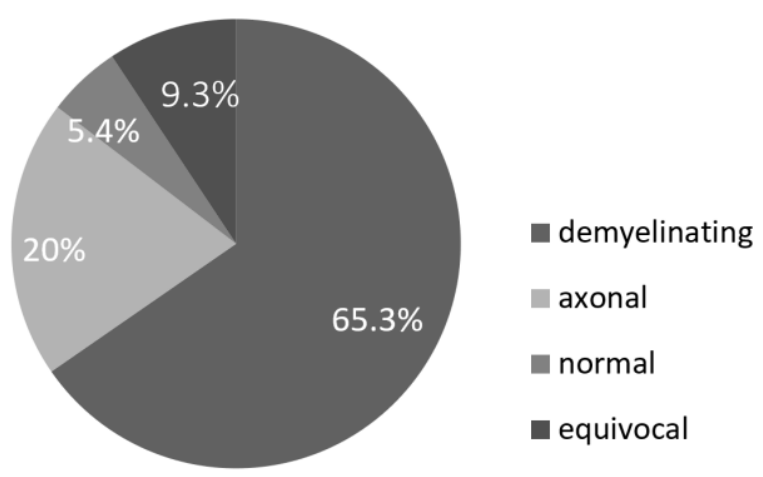

Figure 2: Electrophysiological subtypes based on Hadden criteria.

We classified the time of arrival as early ( $<14$ days) and late ( $\geq 14$ days). The mean values of CMAP, conduction velocity and distal latency were almost normal for the motor nerves tested early and late in all nerves (Table 3). There was no time dependence for the sensory nerves responses, but small-amplitude responses were more prevalent in the upper extremities, and absent sensory responses were more prevalent in the lower extremities. The normal recording was observed more on n.suralis than others, so it was likely to be sural sparing. The number of absent sensory responses increased equally on the upper and lower extremities after the $14^{\text {th }}$ day (Table 4). The normal $\mathrm{F}$ waves were higher in the upper extremities, especially in n.medianus, whereas a very small percentage remained normal in the lower extremities. The absent and prolonged $\mathrm{F}$-waves are more pronounced in n.ulnaris and $n$.tibialis after 14 days (Table 5).

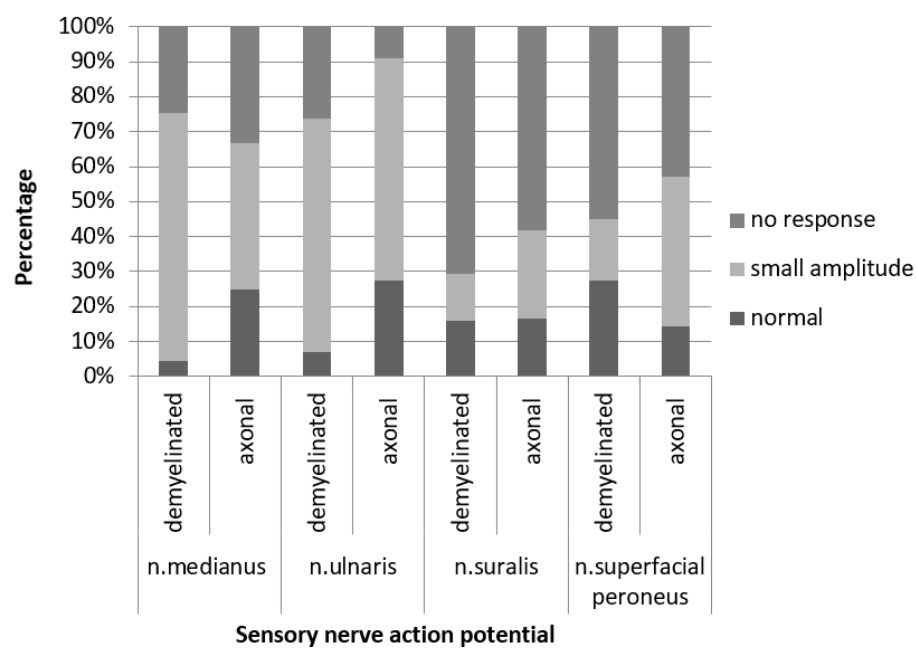

Figure 3: Results of sensory nerve conduction studies.

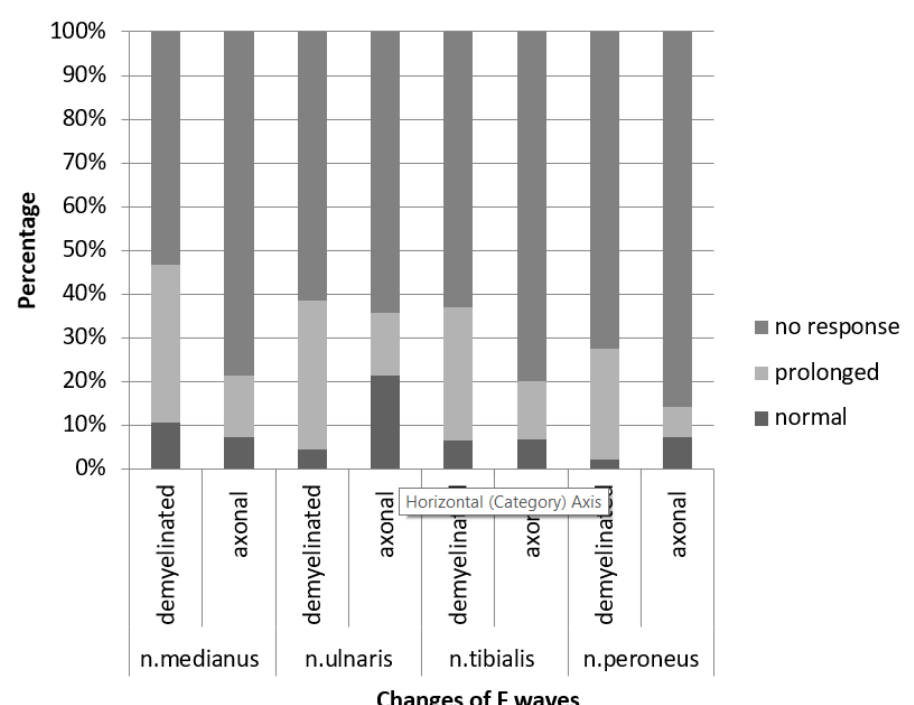

Figure 4: Results of $\mathrm{F}$ waves changes.

\subsection{DISCUSSION}

This retrospective study showed that an incidence of demyelinating subtype (65.3\%) is predominant in Mongolia. In some Asian countries, the axonal subtype is predominant such as China and Bangladesh (54-65\%), while in most countries, the prevalence of axonal subtype is higher than in Europe and America (4-11\%), but demyelinating subtype is predominant in these countries (Bae et al., 2014). This incidence is lower than 
Table 1: Demographics and features of demyelinating and axonal subtypes.

\begin{tabular}{|c|c|c|c|c|}
\hline Variables & Demyelinating & Axonal & $\begin{array}{c}\text { Others (normal and } \\
\text { equivocal) }\end{array}$ & $P$ value \\
\hline \multicolumn{5}{|c|}{ Demographics } \\
\hline Age & $46.2 \pm 15.9$ & $48 \pm 14.5$ & $39.7 \pm 12.0$ & 0.583 \\
\hline \multicolumn{5}{|l|}{ Sex } \\
\hline Male & $23(46.9 \%)$ & $7(46.7 \%)$ & $3(27.3 \%)$ & \multirow{2}{*}{0.461} \\
\hline Female & $26(53.1 \%)$ & $8(53.3 \%)$ & $8(72.7 \%)$ & \\
\hline \multicolumn{5}{|c|}{ Others } \\
\hline \multicolumn{5}{|l|}{ Antecedent events } \\
\hline URI* & $4(8.2 \%)$ & $2(13.3 \%)$ & $1(9 \%)$ & \multirow{4}{*}{0.219} \\
\hline Diarrhoea & $9(18.4 \%)$ & $4(26.7 \%)$ & $3(27.3 \%)$ & \\
\hline Others & $9(18.4 \%)$ & $4(26.7 \%)$ & $4(36.4)$ & \\
\hline None & $27(55.1 \%)$ & $5(33.3 \%)$ & $3(27.3 \%)$ & \\
\hline \multicolumn{5}{|l|}{ Season } \\
\hline Spring & $16(32.7 \%)$ & $4(26.7 \%)$ & $2(18.2 \%)$ & \multirow{4}{*}{0.908} \\
\hline Summer & $9(18.4 \%)$ & $4(26.7 \%)$ & $3(27.2 \%)$ & \\
\hline Autumn & $17(34.7 \%)$ & $5(33.3 \%)$ & $4(36.4 \%)$ & \\
\hline Winter & $7(14.3 \%)$ & $2(13.3 \%)$ & $2(18.2 \%)$ & \\
\hline \multicolumn{5}{|c|}{ Days until NCSs** examination } \\
\hline$<7 x$ & $16(32.8 \%)$ & $7(46.7 \%)$ & $4(36.4 \%)$ & \multirow{3}{*}{0.512} \\
\hline $7-14$ & $17(34.4 \%)$ & 2 (13.3\%) & 6 (54.6\%) & \\
\hline$>14$ & $16(32.8 \%)$ & $6(40 \%)$ & 1 (9\%) & \\
\hline
\end{tabular}

*URI: upper respiratory infection; **NCSs: nerve conduction studies.

Table 2: Results of motor nerve conduction studies.

\begin{tabular}{llcccc}
\hline Nerves & & Normal range & Demyelinating & Axonal & P value \\
& & & & & \\
\hline n.medianus & $\mathrm{CMAP}^{*}(\mathrm{mV})$ & $>3.5$ & $3.8 \pm 3.2$ & $2.4 \pm 3.5$ & 0.534 \\
& $\mathrm{DL}^{* *}(\mathrm{~ms})$ & $<4.2$ & $5.8 \pm 3.7$ & $3.4 \pm 1.5$ & 0.025 \\
& $\mathrm{CV}^{* * *}(\mathrm{~m} / \mathrm{s})$ & $>48$ & $48.6 \pm 13.8$ & $56.8 \pm 17.6$ & 0.816 \\
\hline n.ulnaris & $\mathrm{CMAP}(\mathrm{mV})$ & $>2.8$ & $4.4 \pm 3.2$ & $2.7 \pm 3.6$ & 0.877 \\
& $\mathrm{DL}(\mathrm{ms})$ & $<3.4$ & $3.9 \pm 1.9$ & $2.7 \pm 3.3$ & 0.021 \\
& $\mathrm{CV}(\mathrm{m} / \mathrm{s})$ & $>49$ & $52.0 \pm 13.4$ & $57.9 \pm 9.3$ & 0.137 \\
\hline n.peronealis & $\mathrm{CMAP}(\mathrm{mV})$ & $>2.5$ & $1.5 \pm 1.4$ & $0.6 \pm 0.5$ & 0.001 \\
& $\mathrm{DL}(\mathrm{ms})$ & $<5.5$ & $6.1 \pm 3.8$ & $4.2 \pm 1.7$ & 0.010 \\
& $\mathrm{CV}(\mathrm{m} / \mathrm{s})$ & $>40$ & $34.6 \pm 15.6$ & $47.5 \pm 14.9$ & 0.192 \\
\hline n.tibialis & $\mathrm{CMAP}(\mathrm{mV})$ & $>2.9$ & $3.6 \pm 3.7$ & $2.8 \pm 4.1$ & 0.852 \\
& $\mathrm{DL}(\mathrm{ms})$ & $>6.0$ & $6.4 \pm 3.8$ & $3.8 \pm 1.7$ & 0.090 \\
& $\mathrm{CV}(\mathrm{m} / \mathrm{s})$ & $>41$ & $34.7 \pm 12.0$ & $38.1 \pm 14.7$ & 0.292 \\
\hline
\end{tabular}

*CMAP: compound muscle action potential; **DL: distal latency; ${ }^{* * * C V: ~ c o n d u c t i o n ~ v e l o c i t y ; ~}$

China and Bangladesh but higher than Western countries. To compare with the result of a retrospective study conducted in Russia, AIDP (78\%) and axonal subtype $(22 \%)$ had a very similar result to our study (Supenova et al., 2011). In China, the predominance of axonal subtype has been gradually decreasing over the past few years, and demyelinating (57\%) and axonal subtype $22 \%$ in the southwest region of China were observed in a single study which was close to the result of this study (Zhang et al., 2015). However, AMAN is the most common subtype in Northern China (55.8\%) (Tian et al., 2019). The prevalence of GBS electrophysiological subtypes appears to be close to that of Southwest China. GBS is a post-infectious disorder. Two-thirds of adult patients report preceding respiratory or gastrointestinal tract infection symptoms within four weeks of disease onset (Mazen \& Richard, 2014). In this study, the proportion of pre-infection factors was lower than in other studies. Whereas the seasonal trend of GBS was not mentioned in most studies, some Asian 
Table 3: Motor nerve conduction changes in time groups

\begin{tabular}{llcccc}
\hline Motor nerves & Variables & References & $<14$ days & 114 days & $\boldsymbol{P}$ value \\
\hline n.medianus & $\mathrm{CMAP}^{*}(\mathrm{mV})$ & $>3.5$ & $3.8 \pm 3.4$ & $3.7 \pm 3.1$ & 0.229 \\
& $\mathrm{DL}^{* *}(\mathrm{~ms})$ & $<4.2$ & $5.1 \pm 3.4$ & $4.7 \pm 2.7$ & 0.593 \\
& $\mathrm{CV}^{* * *}(\mathrm{~m} / \mathrm{s})$ & $>48$ & $54.0 \pm 12.6$ & $46.9 \pm 17.3$ & 0.209 \\
\hline n.ulnaris & $\mathrm{CMAP}(\mathrm{mV})$ & $>2.8$ & $4.4 \pm 3.4$ & $4.3 \pm 3.2$ & 0.836 \\
& $\mathrm{DL}(\mathrm{ms})$ & $<3.4$ & $3.3 \pm 1.6$ & $3.9 \pm 1.8$ & 0.101 \\
& $\mathrm{CV}(\mathrm{m} / \mathrm{s})$ & $>49$ & $55.1 \pm 12.8$ & $53.1 \pm 12.1$ & 0.913 \\
\hline n.peronealis & $\mathrm{CMAP}(\mathrm{mV})$ & $>2.5$ & $1.6 \pm 1.8$ & $1.27 \pm 1.3$ & 0.198 \\
& $\mathrm{DL}(\mathrm{ms})$ & $<5.5$ & $5.4 \pm 3.0$ & $5.7 \pm 4.2$ & 0.195 \\
& $\mathrm{CV}(\mathrm{m} / \mathrm{s})$ & $>40$ & $40.3 \pm 16.9$ & $36.6 \pm 16.6$ & 0.918 \\
\hline n.tibialis & $\mathrm{CMAP}(\mathrm{mV})$ & $>2.9$ & $4.7 \pm 4.4$ & $2.9 \pm 3.56$ & 0.351 \\
& $\mathrm{DL}(\mathrm{ms})$ & $<6.0$ & $5.6 \pm 2.4$ & $5.5 \pm 5.0$ & 0.060 \\
& $\mathrm{CV}(\mathrm{m} / \mathrm{s})$ & $>41$ & $39.6 \pm 13.3$ & $33 . \pm 16.1$ & 0.107 \\
\hline
\end{tabular}

*CMAP: compound muscle action potential; ${ }^{* * D L}$ distal latency; ${ }^{* * * C V:}$ conduction velocity;

Table 4: Sensory nerve conduction changes in time groups

\begin{tabular}{|c|c|c|c|c|}
\hline Sensory nerves & Variables (\%) & $<14$ days & $\geq 14$ days & $P$ value \\
\hline \multirow[t]{3}{*}{ n.medianus } & Absent & 17.4 & 33.3 & \\
\hline & Small amplitude & 67.4 & 57.41 & 0.786 \\
\hline & Normal & 15.2 & 9.5 & \\
\hline \multirow[t]{3}{*}{ n.ulnaris } & Absent & 14.6 & 27.3 & \\
\hline & Small amplitude & 70.7 & 59.1 & 0.381 \\
\hline & Normal & 14.6 & 13.6 & \\
\hline n.superfacial & Absent & 58.7 & 70.0 & \\
\hline \multirow[t]{2}{*}{ peronealis } & Small amplitude & 15.2 & 15.0 & 0.761 \\
\hline & Normal & 26.1 & 15.0 & \\
\hline \multirow[t]{3}{*}{ n.suralis } & Absent & 45.0 & 62.5 & \\
\hline & Small amplitude & 27.5 & 96.3 & 0.172 \\
\hline & Normal & 27.5 & 31.3 & \\
\hline
\end{tabular}

Table 5: $\mathrm{F}$ wave changes in time groups

\begin{tabular}{|c|c|c|c|c|}
\hline F waves & Variables (\%) & $<14$ days & $\geq 14$ days & $P$ value \\
\hline \multirow[t]{3}{*}{ n.medianus } & Absent & 57.1 & 43.5 & \\
\hline & Normal & 14.3 & 30.4 & 0.336 \\
\hline & Prolonged & 28.6 & 26.1 & \\
\hline \multirow[t]{3}{*}{ n.ulnaris } & Absent & 59.2 & 45.0 & \\
\hline & Normal & 20.4 & 10.0 & 0.169 \\
\hline & Prolonged & 20.4 & 45.0 & \\
\hline \multirow[t]{3}{*}{ n.peronealis } & Absent & 66.0 & 54.5 & \\
\hline & Normal & 10.0 & 13.6 & 0.370 \\
\hline & Prolonged & 24.0 & 31.8 & \\
\hline \multirow[t]{3}{*}{ n.tibialis } & Absent & 67.2 & 65.2 & \\
\hline & Normal & 8.3 & 4.3 & 0.562 \\
\hline & Prolonged & 24.5 & 30.4 & \\
\hline
\end{tabular}


countries had seasonal distribution, some Asian countries such as in China and Bangladeshi axonal subtype was determined in youth men, in summer after diarrhoea but our study had opposite results, all ages and both gender were equally affected (Islam et al., 2010; Zhang et al., 2015). The prevalence of the disease increases in spring and autumn, but there is no correlation between electrophysiological subtypes and antecedent events in our study.

Motor nerves, sensory nerves and $F$ waves were no different in examined before and after two weeks. Studies in Iran have shown similar results. Unlike our study, the absence of sensory nerves responses was more common, especially those evaluated after two weeks (Yadegari et al., 2014). Recent studies have shown that electrophysiological subtypes could change over serial NCSs and these changes are time-dependent. (Hiraga et al., 2005; Rath et al., 2021) A study by Uncini \& Kuwabara (2021) revealed that $22-38 \%$ of subtypes were shifted from normal, equivocal or AIDP subtypes to axonal GBS. Only $10 \%$ of patients were re-examined in our study, and it showed the follow-up of patients were insufficient to control for the disease. In the future, it is important to analyze serial electrophysiological examination, and we can determine how it transforms primary electrophysiological subtypes of GBS.
Our study has some limitations. We did not test any antecedent infections such as Campylobacter jejuni, and a few electrophysiological studies were not recorded in some patients. The advantage of our study is that until 2019, the Reflex Neurological Clinic was the only hospital in Mongolia that performs NCSs testing. Therefore, all patients with GBS during the study period were included in our study.

\subsection{CONCLUSIONS}

We conclude that the acute inflammatory demyelinating neuropathy was the most common subtype in Mongolian adult patients with Guillain-Barré syndrome.

Acknowledgements: This research did not receive any specific grant from the public, commercial, or not-for-profit funding agencies.

Author Contributions: GG, MR, SJ and BD conceived and designed the study; GG and MR collected data; GG and BD analyzed the data; SJ contributed analysis tools; $G G$ and $B D$ wrote the paper.

Conflicts of Interest: The authors declare no conflict of interest.

\section{References}

Asian Development Bank. (2020). "Overview of Mongolia's water resource system and management" A country water system assessment. https://doi.org/10.22617/TCS200202-2

Bae, J. S., Yuki, N., Kuwabara, S., Kim, J. K., Vucic, S., Lin, C. S., \& Kiernan, M. C. (2014). Guillain-Barré syndrome in Asia. Journal of Neurology, Neurosurgery and Psychiatry, 85(8), 905-911. https://doi.org/10.1136/innp-2013-306212

Burns, T. M. (2008). Guillain-Barré syndrome. Seminars in Neurology, 28(2), 152-167. https://doi.org/10.1055/s-2008-1062261

Doets, A. Y., Verboon, C., van den Berg, B., Harbo, T., Cornblath, D. R., Willison, H. J., Islam, Z., Attarian, S., Barroso, F. A., Bateman, K., Benedetti, L., van den Bergh, P., Casasnovas, C., Cavaletti, G., Chavada, G., Claeys, K. G., Dardiotis, E., Davidson, A., van Doorn, P. A., ... Zivkovic, S. (2018). Regional variation of Guillain-Barré syndrome. Brain, 141(10), 28662877. https://doi.org/10.1093/brain/awy232

Doorn, P. A. Van. (2020). Guillain-Barré syndrome. In Dysimmune Neuropathies. Elsevier Inc. https://doi.org/10.1016/B978-0-12-814572-2.00002-9

Feasby, T. E., Gilbert, J. J., Brown, W. F., Bolton, C. F., Hahn, A. F., Koopman, W. F., \& Zochodne, D. W. (1986). An acute axonal form of guillain-barrée polyneuropathy. Brain, 109(6), 1115-1126. https://doi.org/10.1093/brain/109.6.1115

Hadden, R. D. M., Cornblath, D. R., Hughes, R. A. C., Zielasek, J., Hartung, H. P., Toyka, K. V., \& Swan, A. V. (1998). Electrophysiological classification of Guillain-Barre syndrome: Clinical associations and outcome. Annals of Neurology, 44(5), 780-788. https://doi.org/10.1002/ana.410440512

Hiraga, A., Kuwabara, S., Ogawara, K., Misawa, S., Kanesaka, T., Koga, M., Yuki, N., Hattori, T., \& Mori, M. (2005). Patterns and serial changes in electrodiagnostic abnormalities of axonal Guillain-Barré syndrome. Neurology, 64(5), 856-860. https://doi.org/10.1212/01.WNL.0000153071.71335.E9

Islam, Z., Jacobs, B. C., Van Belkum, A., Mohammad, Q. D., Islam, M. B., Herbrink, P., Diorditsa, S., Luby, S. P., Talukder, K. A., \& Endtz, H. P. (2010). Axonal variant of Guillain-Barré syndrome associated with Campylobacter infection in Bangladesh. Neurology, 74(7), 581-587. https://doi.org/10.1212/WNL.0b013e3181cff735

Kimura, J. (2013). Electrodiagnosis in Diseases of Nerve and Muscle: Principles and Practice (4th ed.). Oxford University Press. https://doi.org/10.1093/med/9780199738687.001.0001 
Kuwabara, S., \& Yuki, N. (2013). Axonal Guillain-Barré syndrome: Concepts and controversies. The Lancet Neurology, 12(12), 1180-1188. https://doi.org/10.1016/S1474-4422(13)70215-1

Mazen, M. D., \& Richard, J. B. (2014). GBS and Variants. NIH Public Access, 31(2), 491-510. https://doi.org/10.1016/j.ncl.2013.01.005.Guillain-Barr

Papri, N., Islam, Z., Leonhard, S. E., Mohammad, Q. D., Endtz, H. P., \& Jacobs, B. C. (2021). Guillain-Barré syndrome in lowincome and middle-income countries: challenges and prospects. Nature Reviews Neurology, 17(5), $285-296$. https://doi.org/10.1038/s41582-021-00467-y

Rath, J., Schober, B., Zulehner, G., Grisold, A., Krenn, M., Cetin, H., \& Zimprich, F. (2021). Nerve conduction studies in GuillainBarré syndrome: Influence of timing and value of repeated measurements. Journal of the Neurological Sciences, 420, 117267. https://doi.org/10.1016/i.jns.2020.117267

Shahrizaila, N., Lehmann, H. C., \& Kuwabara, S. (2021). Guillain-Barré syndrome (seminar). Lancet, 397, $1214-1228$. https://doi.org/10.1016/S0140-6736(21)00517-1

Suponeva, N. A., Mochalova, E. G., Grishina, D. A., \& Piradov, M. A. (2014). The specific features of Guillain-Barre syndrome in Russia: Analysis of 186 cases. Neuromuscular Diseases, 1, 37-46. https://doi.org/10.17650/2222-8721-2014-0-1-40-47

Tian, J., Cao, C., Li, T., Zhang, K., Li, P., Liu, Y., \& Liu, X. (2019). Electrophysiological subtypes and prognostic factors of GuillainBarre syndrome in northern China. Frontiers in Neurology, 10(JUL), 1-7. https://doi.org/10.3389/fneur.2019.00714

Uncini, A., \& Kuwabara, S. (2021). The electrodiagnosis of Guillain-Barré syndrome subtypes : Where do we stand ? Clinical Neurophysiology The electrodiagnosis of Guillain-Barré syndrome subtypes : Where do we stand ? Clinical Neurophysiology, 129(12), 2586-2593. https://doi.org/10.1016/j.clinph.2018.09.025

Willison, H. J., Jacobs, B. C., \& van Doorn, P. A. (2016). Guillain-Barré syndrome. The Lancet, 388(10045), $717-727$. https://doi.org/10.1016/S0140-6736(16)00339-1

Yadegari, S., Nafissi, S., \& Kazemi, N. (2014). Comparison of electrophysiological findings in axonal and demyelinating GuillainBarre syndrome. Iranian Journal of Neurology, 13(3), 138-143.

Zhang, G., Li, Q., Zhang, R., Wei, X., Wang, J., \& Qin, X. (2015). Subtypes and prognosis of Guillain-Barré syndrome in southwest China. PLoS ONE, 10(7), 1-8. https://doi.org/10.1371/journal.pone.0133520 